\title{
On the Cultural Factors and the English Teaching
}

\author{
Zhen Zhou \\ Foreign Languages College, Nanchang Normal University, Nanchang, Jiangxi, 330032 \\ zoye100@sina.com
}

\begin{abstract}
Keywords: Culture; Language communication; Information acquiring; the English teaching; Cultural comparison
\end{abstract}

\begin{abstract}
The language is the carrier of culture, which is also an important part of culture. And the language teaching cannot be separated from cultural teaching. The ultimate goal of English teaching is not only to cultivate students' language using ability, but also the communicative abilities. However, at present, the English teaching focuses on the language imparting but neglects students' cultural teaching. The article firstly explains the relationship between culture and the language learning, then analyzes the impact of culture on the language communication and English teaching, explores the principles of cultural teaching, and lastly puts forward some strategies to implement the cultural teaching more effectively. Thus, the English teachers should not only focus on imparting necessary language knowledge and skills, but also should attach more attention to fostering students' cultural communicative ability. The article attempts to offer some teaching reference for the English teaching to improve students' trans-cultural communicative ability and ultimately boost the English teaching quality.
\end{abstract}

\section{Culture and the Language Learning}

It is well-known that language is an important communicative form emerging in the process of human's evolution and development. Culture refers to thoughts, habits, and customs which come into being in the human's survival and living environment, which is reflected in different areas closely related to our life and is the knowledge formed through long-time exploring from our society, history or our experience. As for the relationship between cultural factors and the English learning, it is obvious that the language itself is the cultural product in the process of human social development. The language belongs to culture, and at the same time, the expression and inheriting of culture must be carried out by language forms. The language is also of great importance to culture. They are co-existent and interdependent. What's more, since the developing process of the language and culture is based on the human social life, every nation forms different cultures and specific language, there are differences in the language and culture in different peoples. Therefore, culture and the language is a crucial and basic factor to distinguish different nations.

\section{The Impact of Culture on the Language Communication}

In human's communication, people often come across things related to culture. Especially, in the English communication, the cultural factors we meet have distinct differences from our national culture. Hence, we should have a correct awareness and knowledge about the western culture, and only in this way, can we use English correctly and freely and achieve a better communicative effect.

The Impact of Culture on Information Acquiring. Firstly, culture affects human's acquiring of information. Because people from different backgrounds possess different thinking styles and values, when they describe something or understand some language, they will present totally different views. Or because of not knowing the different culture of the target language, people do poor in translation. There are two reasons accounting for the impact of the culture on the acquiring of information. First, when using English to communicate with native English speakers, we tend to have some misunderstanding due to the differences of national cultures, and we often meet some communicative impediments. Second, because of different cultures reflected in the language, people can know the basic meaning of the 
language, but they could not figure out the implied meaning, which requires people to know more about correspondent cultural values and traditions.

Cultural Differences Misleading the Information Acquiring. As the differences of national culture are obvious, different nations hold different, unique attitudes and concepts. In our communication with native English speakers, if we do not have deep understanding of the target language culture and view the language involved in the English communication from the perspective of our China's culture concept, we will get wrong information transfer. As is well-known, but as to different histories and environments, there are clear regional features in the cultures of differences and nations. For example, the view on something may be positive in China, but it may be negative in the western culture. If we could not accurately grasp the distinct differences, we will misunderstand the acquired information due to the differences of culture and concepts. Besides, the two parties tend to start from their own culture when communicating in English with foreigners. Thus, it will lead some errors in the language communication. Although the meaning of language maybe does not change, it also distorts the original meaning we want to convey, which prevents the communicative activity from achieving a satisfying effect.

\section{The Impact of Culture on the English Teaching}

The importance of cultivating students' cultural ability cannot be denied. The alternating teaching aim of English teaching is to cultivate students' English communicative ability. The English communicative ability not only includes the language using ability, but also includes the comprehensive language ability to use the basic language structure, that is, grammatical ability, language comprehension ability, social language ability, and language strategic ability. The language comprehension ability and social language ability mean that based on the comprehension of culture of English countries, combining actual English culture factors, we do some language communication selectively. Besides, because we must take the context into consideration to comprehend some particular language, we can understand the language meaning better and more accurately. These demands on grasping language environment and culture mean that it is important for students to improve their English communicative ability through learning culture of English speaking countries.

\section{The Principle of Cultural Teaching}

In the cultural teaching, we can not only teach the culture in the English speaking countries merely, or put all the English culture in the teaching, we should combine the English culture with our Chinese culture through communicative ways and we should often compare the two cultures and understand the foreign culture from the Chinese culture. In the cultural teaching, as to the teaching content and teaching forms, we should abide by some rules, in order to ensure the fulfillment of cultural teaching aims.

Culture Comparison. When teaching English, we can not only teach English culture unilaterally and we should compare the English culture and Chinese traditional and modern culture, and focus more on the differences. Through the learning of cultural differences, we can understand different features more effectively. The principle of comparison can avoid the whole accepting of the western culture. Through comparison, we can understand the excellent parts of the two different cultures, and expand these excellent cultural factors more effectively and it is of great help to build and develop students' cultural values.

Culture Assimilation. The teacher should develop the positive and good parts of the two cultures, absorb selectively the western culture, integrate with our own culture and form comprehensive culture with unique educational characteristics. In our English teaching, we should guarantee the basic status of our own culture and view the English culture problems from the two angles of our Chines culture and the foreign culture. We cannot accept all English culture wholly, or resist the English culture blindly. We should understand the communicative demand of English through all-around understanding of the western English culture. And we should carry out effective management and reasonable utilization and penetrate our culture into the English communicative behavior. On the other hand, we should refer to 
the positive and essence ideas of the English culture and integrate with our culture to form new modernized and internationalized cultural values.

Being Related to the English Textbook. This principle means that the English cultural teaching should be based on the English teaching content and textbook. In the choice of English cultural teaching, we should extract cultural teaching resources according to different teaching courses and books. And only in this way, can the cultural teaching be solid and meaningful. After choosing correct cultural content as teaching accordance, students can learn English culture more effectively with the textbook content and the cultural content teachers choose properly for them.

Gradual Process. The principle means that the cultural teaching should develop from easy content to harder content step-by-step and consider different stages from behavioral habits to psychological state. At first, the teacher should enable students to adapt and learn English cultural teaching. Secondly, we should enhance students' understanding of the two cultures and boost students' confidence to learn the cultural differences. At last, through right teaching and proper guidance, the teacher enables students to have the ability to control and utilize. It is a gradual developing process to adapt to another culture, so the teacher should also take consideration of the variety and complexity of different cultures and enable students to make a wise choice as to the type of culture they need.

\section{The Strategies of Cultural Teaching}

The principle of cultural teaching is illustrated above, and we should explore suitable cultural teaching ways in order to fulfill the ultimate goal of cultural teaching through specializing the methods. Before formulating English cultural teaching methods, we should analyze and research some foreign advanced foreign language teaching methods, combine the uniqueness of our own culture and the western culture, and establish a complete system of English culture teaching methods based on advanced teaching theory. The strategies of cultural teaching are as follows:

Cultural Comparison. This is the most basic cultural teaching method and is widely used and approved in advanced and scientific foreign language cultural teaching. This method can enable students to accept foreign cultures more easily and deepen their understanding of their own culture through comparing similarities and differences of the two cultures. Besides, this method can not only deepen students' impression of their own culture and their cognitive level, but also increase the fun of learning, stimulate students' positive learning emotion.

Cultural Insertion. It means integrating the cultural learning and English language teaching. The teacher should add cultural teaching content timely when involving English culture, combine the English language teaching and cultural teaching, and try to achieve a better English teaching effect.

Cultural Assimilation. We can combine the cultural values of English countries with China's culture, assimilate similar cultural factors and westernize Chinese culture or sinicize the western culture centering on the easily changeable factors in the two cultures. Moreover, as for the cultural factors with more distinct differences, in order to avoid cultural conflict or dispute, we should use the cultural assimilation way to enable students to gradually accept the western cultural factors, who live in our China's cultural environment and have personal values.

Cultural Capsule. We can categorize students' cultural learning according to different cultural content and factors, for example, history, geography, food, clothing, nationality, religion, education and so on. This method is of great significance to learn western country culture in a systematic way.

Cultural Corner. The English teacher can use the teaching facilities, media and campus environment to establish special areas for English speaking country culture. Through different kinds of content and cultural scope advocating, students' understanding of English country culture can be deeply strengthened. Teachers and students can set up an English corner, hold English cultural festivals, broadcast English culture radio, play English movies or open English saloons or seminars to create the cultural atmosphere to raise students' interest in knowing the English culture.

Mini-dramas and Plays. It is also called situation teaching. It means that the teacher sets a certain English culture situation, makes students combine the language knowledge and culture teaching and practice their English comprehensive communicative ability in simulated English contexts. 
These English cultural teaching ways mainly focus on improving the traditional English teaching. Besides, the teacher can add the forms of students' extra-curriculum activities; enrich the channels to get into touch with the English culture. The teacher should also improve students' comprehensive understanding and appreciating ability of the English culture.

\section{Conclusion}

In the English teaching, we tend to use the traditional Chinese cultural values and thinking mode to comprehend the English language and communicate with others, which maybe causes many communicative difficulties due to cultural differences, and even leads to some conflicts. Besides, the most basic purpose of the English teaching is not only to foster students' four skills of listening, speaking, reading and writing, but also to cultivate students' communicative ability, that is, the English pragmatic ability. The ultimate goal of language learning is to be able to communicate with others appropriately, which relates to humanistic relations and cultural factors. Therefore, in the English teaching, when adding cultural teaching, we cannot merely teach culture simply, we should use many teaching methods, and integrate all-around English culture teaching into the teaching process. Besides, the school and teacher should do their utmost to expand students' culture receiving channels and make English culture penetrate into students' school life. And at the same time, we should retain our culture's characteristics and deepen our understanding of our own culture in the process of accepting the western culture.

\section{Acknowledgments}

This article was supported by the school project of Nanchang Normal University, named "The research into college students' English learning belief and learning strategy.”(15RWYB21).

\section{References}

[1] Birdwhisted Ray. Kinesics and Context, Philadelphia: Pennsylvania University Press, 1970.

[2] Guojin Hou. The essence of pragmatics: pragmatics versus pragmatic mistakes. Beijing: World Book Publishing House. 2014.

[3] Hall, Joan Kelly. Teaching and researching language and culture. Beijing: Foreign language teaching and research press, 2005.

[4] Huaikui LI. The research into 12 pragmatic ability: theory and practice. Shanghai: Shanghai Jiao Tong University Publishing House. 2013.

[5] Hong Jin. How to develop intercultural communicative competence in English teaching. J. Curriculum, teaching material and method. 2015, 35 (11): 80-85.

[6] Jiawei Lu. The effect of classroom instruction on the development of learners' pragmatic competence in the cognitive framework. Journal of PLA Foreign Languages Institute, 2013, (1):67.

[7] Kramsch, Claire. Language and culture. Shanghai: Shanghai Foreign Language Education Press, 2000.

[8] Lynch, Hanson. Developing cross-cultural competence: a guide for working with young children and their families. Baltimore: Paul Brooks Publishing Company, 1998: 342.

[9] Teng Ma. The interlinguas pragmatic ability of English majors and the training mode. Beijing: China science Publishing House. 2013.

[10] Wenzhong Hu. Overcoming the cultural barriers. Beijing: Foreign Language and Teaching Research Publishing House, 2002:174.

[11] Williams, M. \& Burden, R.L., Students' developing conceptions of themselves as Language Learners, J. The Modern Language. 1997(83): 193-201. 
[12] Xiaoxi Sun. Development on L2 pragmatic competence. Shanghai: Shanghai Jiao Tong University Publishing House. 2009.

[13]Zhanhao Jiang. The research into pragmatic ability in the view of intermediary language pragmatics. Beijing: Beijing University Publishing House. 2013. 